\title{
THE NATURAL HISTORY OF OSTEOID OSTEOMA*
}

\author{
With a Report of Twenty Cases
}

\author{
J. S. R. Golding, University College of the West Inimies
}

Formerly Senior Registrar, Royal National Orthopaedic Hospital, London

Osteoid osteoma was originally described by Jaffe in 1935 . It occurs mainly in the long bones and is characterised by pain and tenderness; radiographs typically show an extensive zone of sclerosis around a central small transradiant area containing stippled calcification. The histological appearance of osteoid tissue in a highly vascular osteoblastic stroma led Jaffe and Lichtenstein (1940) to the conclusion that the lesion was a benign neoplasm. About two hundred cases have been reported (Table I), but the original descriptions of the condition remain unsurpassed. Nevertheless the clinical behaviour of the condition is so unusual for a neoplasm that clinicians have been loath to believe that an inflammatory process was not present. The controversy concerning the etiology of osteoid osteoma was well expressed by Mackenzie (1947), who described two cases under the title "painful non-suppurative localised sclerosis of the long bones."

TABLE I

Site of Lesion in 198 Cases of Osteoid Osteoma

\begin{tabular}{|l|r|r|r|}
\hline \multicolumn{1}{|c}{ Site } & $\begin{array}{c}\text { Reported } \\
\text { cases }\end{array}$ & $\begin{array}{c}\text { Present } \\
\text { series }\end{array}$ & Total \\
\hline Femur & 39 & 2 & 41 \\
Patella & 1 & - & 1 \\
Tibia & 51 & 9 & 60 \\
Foot & 28 & 2 & 30 \\
Scapula & 1 & - & 1 \\
Humerus & 11 & 1 & 12 \\
Forearm & 9 & - & 9 \\
Hand & 14 & 4 & 18 \\
Vertebrae & 19 & 2 & 21 \\
Pelvis & 4 & - & 4 \\
Ribs & 1 & - & 1 \\
\hline \multicolumn{1}{|c}{ Total } & 178 & 20 & 198 \\
\hline
\end{tabular}

TABLE II

Age Incidence in 198 Cases of Osteoid Osteona

\begin{tabular}{|cc|c:c|}
\hline $\begin{array}{c}\text { Age } \\
\text { years })\end{array}$ & $\begin{array}{c}\text { Reported } \\
\text { cases }\end{array}$ & $\begin{array}{c}\text { Present } \\
\text { series }\end{array}$ & Total \\
\cline { 1 - 4 } $1-5$ & 10 & - & 10 \\
$6-10$ & 19 & 1 & 20 \\
$11-15$ & 44 & 6 & 50 \\
$16-20$ & 46 & 6 & 52 \\
$21-25$ & 29 & 3 & 32 \\
$26-30$ & 17 & 3 & 20 \\
$31-35$ & 7 & 1 & 8 \\
Over 36 & 3 & - & 3 \\
Not known & 3 & - & 3 \\
\hline Total & 178 & 20 & 198 \\
\hline
\end{tabular}

Twenty case records have been examined, in nineteen of which the diagnosis of osteoid osteoma was confirmed by histological examination. This paper is concerned with observations made on these records, the examination of the microscopical sections and, whenever possible, examination of the patients themselves.

\section{GLINIGAL FEATURES}

Osteoid osteoma affects males more frequently than females. The onset of symptoms is usually during the second decade of life although cases have been reported in patients under five and over forty years of age (Table II).

* Based on a paper read before the Joint Meeting of Orthopaedic Associations of the English-speaking World on June 30, 1952. 
Pain, which is the outstanding clinical feature of the condition, is characteristically severe and poorly localised. It is usually worse at night and many patients have observed the peculiar relief obtained from aspirin and codeine tablets (Table III).

The affected bone may be enlarged and tender over the lesion. Muscle wasting is common and, if the lesion is in a lower limb bone, a limp is usually present. Although the skin may

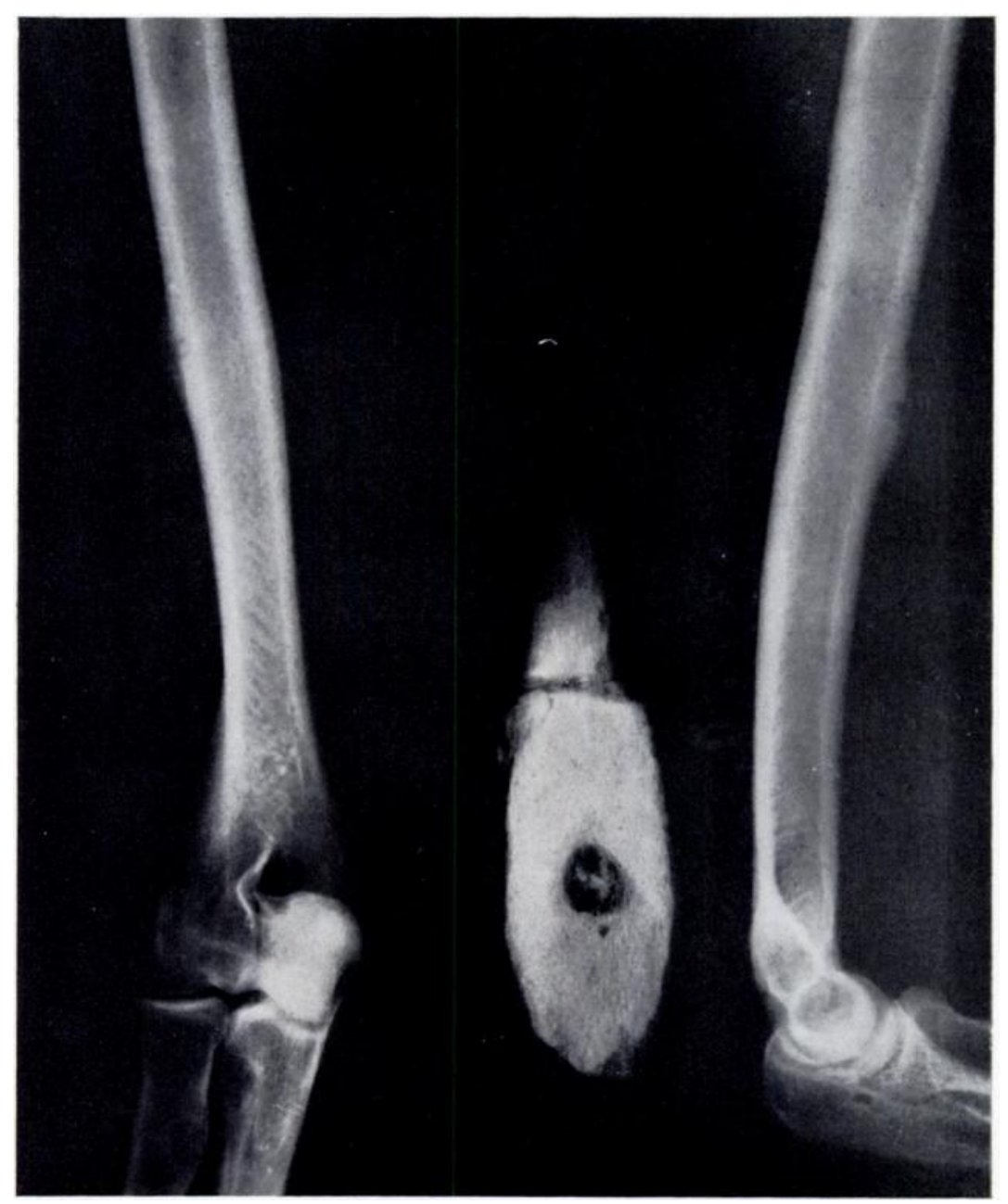

FIG. 1

Case 6-Osteoid osteoma of the shaft of the humerus. The lesion is of the subperiosteal type which frequently resembles a chronic subperiosteal abscess. The slab radiograph shows the cavity which contains the osteoid osteoma, and the highly calcified irregular trabeculae within it.

feel warm over the lesion signs of infection are unusual, but cases with a slight leucocrtosis and enlargement of the regional lymph glands have been reported (Jackson 1949). There is no association with trauma, nor is there any abnormality in serological or blood chemical examinations.

\section{RADIOGRAPHIC APPEARANCE}

The essential radiographic feature of an osteoid osteoma is a zone of bone sclerosis surrounding a small area of transradiancy (Fig. 1). The central area is always small, often merely a "chink" in the bone, and never more than one centimetre in diameter; within

VOL. $36 \mathrm{~B}$, NO. 2, MAY 1954

$\mathrm{D}_{(4)}$ 
it may be seen a nidus of irregular calcification (Fig. 3). The zone of sclerosis is pronounced if the lesion is in cortical bone or on its surface, particularly in young subjects, and may extend far beyond the lesion and, by its density, mask the central area-a difficulty overcome by careful positioning, varying penetration and tomography (Fig. 8). Sclerosis is poorly marked round a lesion in cancellous bone, but comparison of radiographs of both sides reveals its true nature.

TABLE III

Symptoms in Twenty Cases of Osteoid Osteoma

\begin{tabular}{|c|c|c|c|c|c|}
\hline Pain & . & . & . & . & 20 \\
\hline Swelling & . & . & . & . & 11 \\
\hline Tenderness & . & . & . & . & 8 \\
\hline Wasting . & . & . & . & . & 4 \\
\hline Limp & . & . & . & - & 3 \\
\hline \multicolumn{4}{|c|}{ First diagnosis " neurosis". } & . & 5 \\
\hline \multicolumn{3}{|c|}{ Relief by aspirin } & . & . & 9 \\
\hline
\end{tabular}

\section{CASE REPORT}

Case 1 (Mr J. I. P. James's case). Osteoid osteoma of phalanx of finger-A girl aged twenty years complained of pain on attempting to extend the distal interphalangeal joint of the affected finger, of three years' duration. She associated the onset of pain with a cat scratch. The radiograph showed some new bone formation at the base of the terminal phalanx, but the diagnosis was uncertain.

A further radiograph six weeks later showed a small cavity with a ring of sclerosed bone around it and irregular calcification inside (Fig. 3). A diagnosis of Brodie's abscess or osteoid osteoma was suggested. At operation the base of the phalanx was found to be enlarged and rather soft. The softened area was excised. The patient has remained free of pain.

Histological examination (Dr H. A. Sissons) showed an osteoid osteoma consisting of delicate trabeculae of partly calcified bone embedded in a spindle-celled tissue.

In certain cases in which the radiological features are difficult to interpret, the disproportionately severe symptoms of pain and tenderness may well lead to the diagnosis of neurosis.

\section{GASE REPORT}

Case 2 (Sir Reginald Watson-Jones's case). Osteoid osteoma of scaphoid bone-A man aged thirty-three years complained of pain in the right wrist, beginning three weeks after a fall on to the hand. It had been thought that he had fractured the carpal scaphoid bone but, despite immobilisation of the wrist for six months, aching pain had persisted and it was so severe that he had been taking ten aspirin tablets daily. Thereafter his wrist had been manipulated without benefit. He had been told that his disability arose from disuse and that he had " a very considerable functional overlay." In fact he had been discharged from one of the military services as a neurotic. Clinical examination disclosed no abnormality in the wrist or hand except for some wasting of the small muscles, but radiographs showed a small cystic area in the scaphoid with a more dense node which was clearly an osteoid osteoma (Fig. 4). It was removed by drilling through the tubercle of the bone, and next morning the patient said that he was entirely free of the pain that he had had day and night for two years. There was permanent relief.

\section{PATHOLOGICAL FEATURES}

The gross appearance of the lesion varies according to its site and size. When the lesion is large it appears as a vascular friable mass from three to ten millimetres in diameter varying in colour from purple red to light orange and containing gritty particles. This mass lies in a 
distinct cavity to which it is adherent (Fig. 2). The surrounding sclerotic bone contains many blood vessels and the overlying periosteum is thickened.

Sometimes it is difficult to demonstrate the central lesion even on microscopical examination of the sclerosed bone. Serial sections throughout the excised bone may le required before the nidus, lying in a mere chink, is discovered.

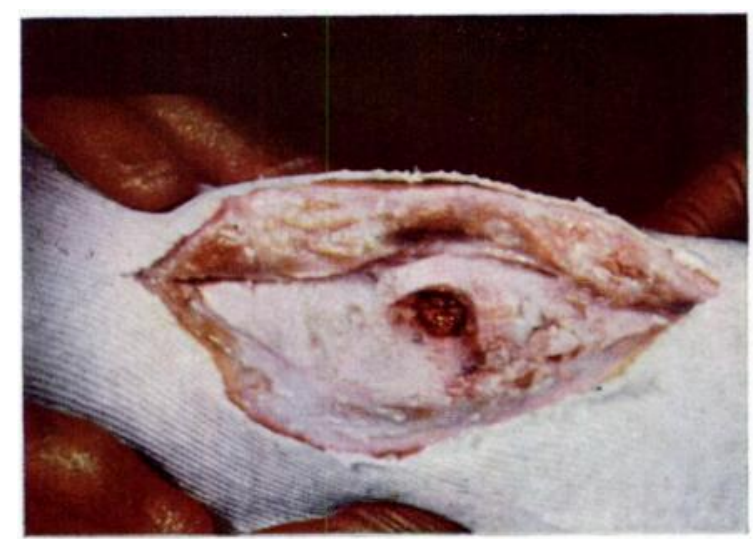

FIG. 2

Case 16-Showing the osteoid osteoma lying in a cavity in the sclerosed bone of the tibia. The vascular appearance of the lesion can be clearly seen.

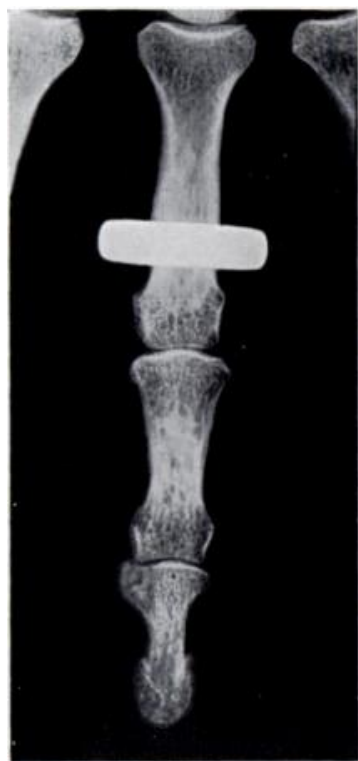

FIG. 3

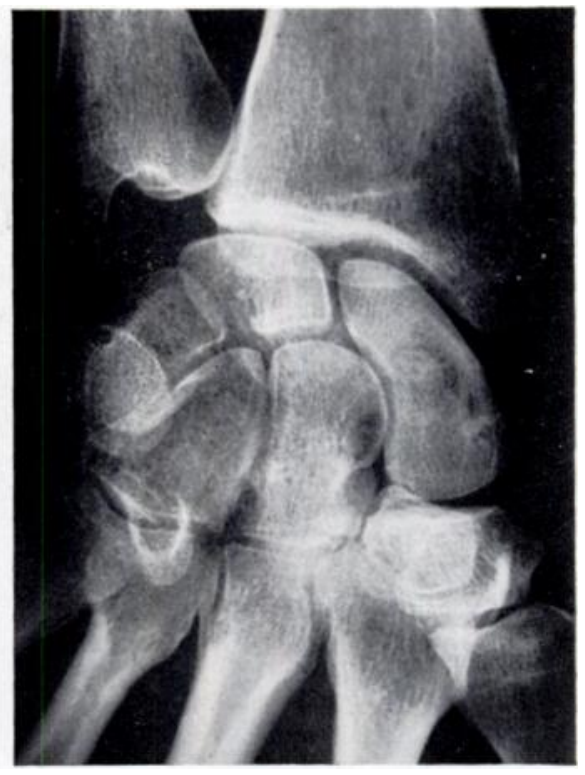

FIG. 4

Figure 3. Case 1-Osteoid osteoma of the base of the terminal phalanx of the ring finger. The nidus can be seen lying in an area of transradiarcy. The lesion lies in cancellous bone and sclerosis is not a feature. Figure 4. Case 2-Osteoid osteoma with well marked nidus in the scaphoid.

The histological appearance varies with the age of the lesion and its site. In general, there is a well circumscribed mass of irregular osteoid tissue lying in a highly vascular stroma of connective tissue containing osteoblastic cells (Fig. 5), and surrounding this are thickened trabeculae of bone with large vascular systems. There are some irregular calcified trabeculae

VOL. $36 \mathrm{~B}$, NO. 2 , MAY 1954

$\mathrm{DI}_{14}$ 
of new bone lying in the osteoid tissue and in older lesions these are frequently pronounced. In general the younger lesions are more highly vascular. There is good evidence that there is homogeneous intense osteoblastic activity throughout the lesion (Fig. 6).

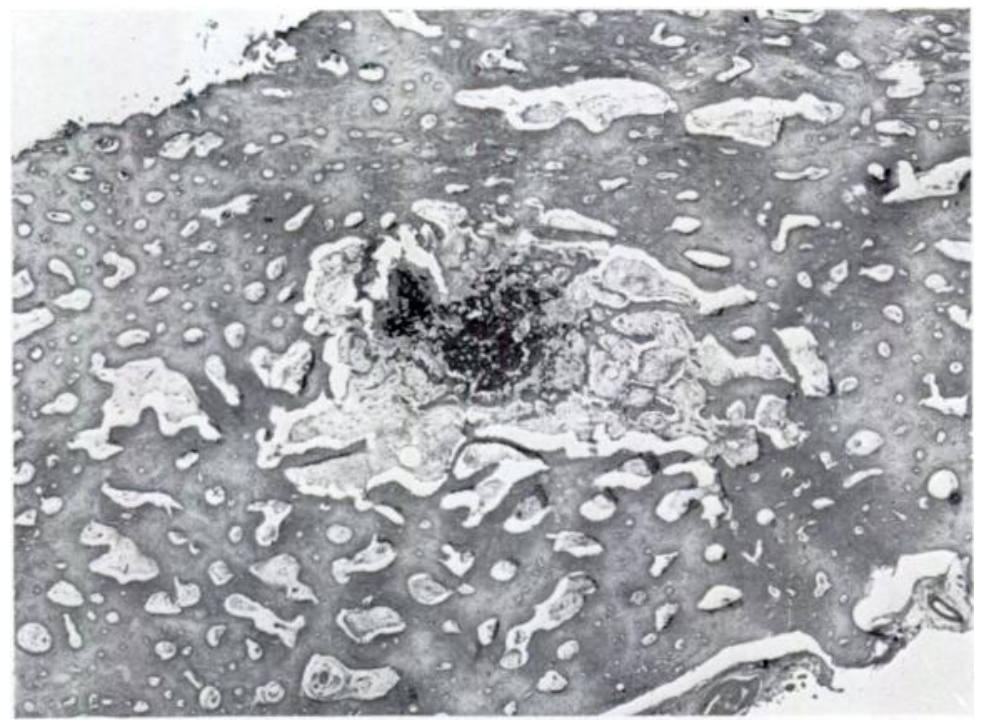

FIG. 5

Case 12-Photomicrograph at low magnification. The osteoid osteoma, stained with haemotoxylin and eosin, stands out clearly from the surrounding cortical bone, which shows evidence of sclerosis.

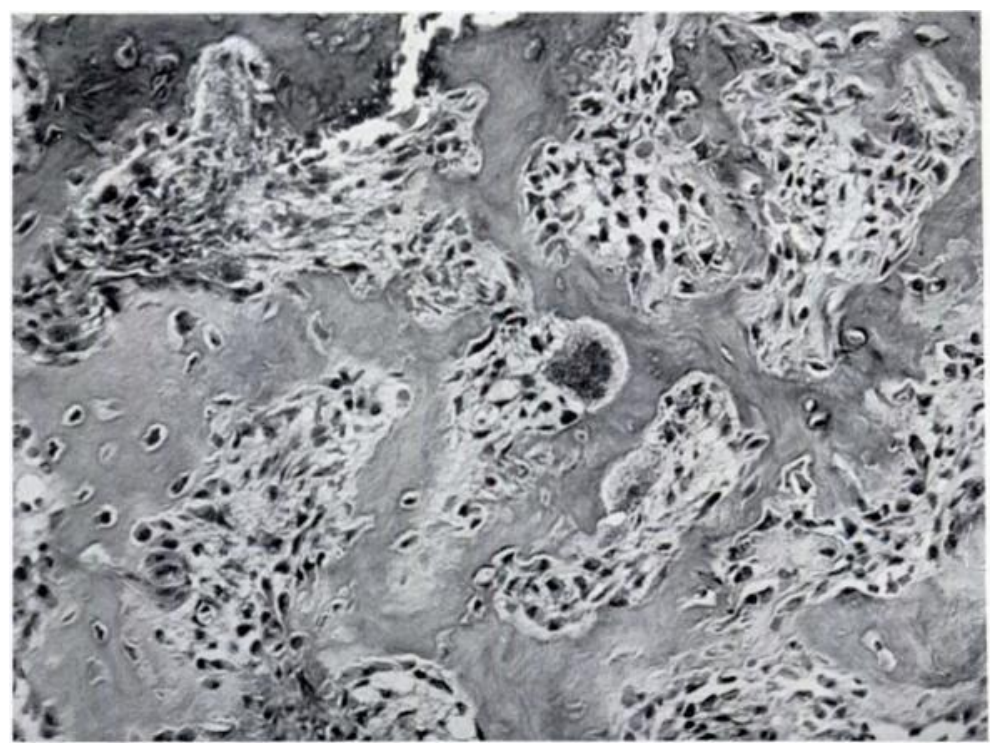

FIG. 6

Case 12-Photomicrograph at high magnification. The osteoblastic nature of the stroma can be clearly seen. There are areas of partly calcified osteoid tissue. Vascular spaces are numerous. There is a large giant-cell near the centre of the field.

\section{DIAGNOSIS}

The main causes of difficulty in arriving at a diagnosis of osteoid osteoma are the severity of the pain, which may be poorly localised by the patient, and the absence of pronounced 
radiological changes in the bone when the lesion lies in the spongiosa. Even when a radiographic abnormality has been observed its significance may not be appreciated as the pain may be referred far from the lesion. Referred pain arises commonly from three sites: 1) the lumbar spine, especially when the pars interarticularis is involved; pain is referred to the abdomen or into the leg (Case 3$) ; 2$ ) the region of the lesser trochanter of the femur, whence pain is commonly referred to the knee (Chandler and Kaell 1950); and 3) the posterior aspect of the upper third of the tibia, whence pain is referred up the thigh to the hip (Vaughan-Jackson 1950).

\section{CASE REPORT}

Case 3 (Mr 1). M. I unn's case). Osteoid osteoma of second lumbar vertebra-A boy of eighteen complained of severe pain in the right side of the upper lumbar region which had been noticed first five months previously when bending. The patient was admitted to hospital where marked spasm of the lumbar muscles was observed. The pain later radiated to the groin and front of the thigh, which was wasted. Radiographs showed an osteolytic lesion in the pars interarticularis of the second lumbar vertebra (Fig. 7).

At operation a cherry red mass was found in a cavity in the pars interarticularis, which was removed with the inferior articular facet which was found to be loose. The second lumbar nerve root was found to be lying directly under the lesion.

Histological examination (Professor W. Newcomb) showed a vascular osteoid osteoma. The patient has remained free from symptoms.

The differential diagnosis is mainly from an inflammatory process, particularly a Brodie's abscess or Garre's type of sclerosing osteomyelitis. These conditions may show similar radiographic appearances but generally the clinical history will make the diagnosis clear. Eosinophilic

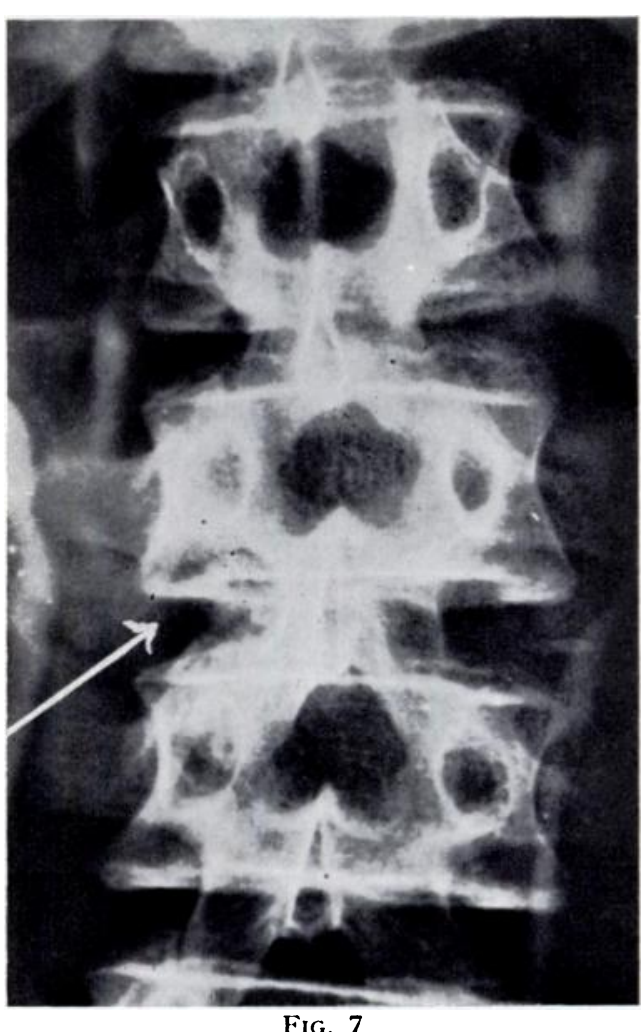
FIG. 7

Case 3-Osteoid osteoma lying in the pars interarticularis of the second lumbar vertebra. It caused severe radiating pain from pressure upon the underlying nerve root.

granuloma may be confused with osteoid osteoma, but these lesions are often multiple and usually larger.

\section{THE NATURAL HISTORY}

There will always be some doubt about the natural history of osteoid osteoma because without biopsy the diagnosis cannot be proved and biopsy must change its normal development. Nevertheless there is considerable indirect evidence that the condition runs a self-limiting course. Sherman (1947) observed that very few examples in patients over thirty years of age have been reported. Moberg (195l) pointed out that no case has been reported in which an adult has had a persistent area of sclerosis in a bone with an antecedent history suggestive of osteoid osteoma.

The only relevant case of which personal knowledge is available concerns a girl who, when thirteen years of age, developed aching in her right shin. The radiograph at that time was very suggestive of an osteoid osteoma with widespread bone sclerosis in the tibia. The pain gradually became more severe and it was suggested that the tibia should be explored. The child's mother refused to allow this, and so it has been possible to follow the case, so far for six years. A recent radiograph still shows a similar appearance, although the symptoms have almost disappeared. It is therefore believed, as suggested by Moberg (19:51) and Sherman

vol. $36 \mathrm{~B}$, No. 2, MAY 1954

$\mathrm{D} 2_{(8)}$ 
(1947), that an osteoid osteoma is a self-limiting condition running a benign course giving symptoms of varying severity over a period of about six years.

Dockerty, Ghormley and Jackson (1951) reported a case history with features strongly suggestive of an osteoid osteoma in the epiphysis at the upper end of the left femur in a girl of seven. This case was followed for six years, by which time she was free from symptoms, although the radiograph still showed considerable sclerosis. It seems probable that the bone sclerosis around the lesion gradually disappears as the trabeculae become reorientated to the normal lines of stress.

\section{DISCUSSION}

There are two clear schools of thought concerning the nature of osteoid osteoma: some believe that it is a benign neoplasm, whereas others (Compere 1932, Brown and Ghormley 1943) argue that it is an abortive form of osteomyelitis. Jaffe carefully weighed up the available evidence and concluded that the lesion must be a benign neoplasm. His evidence is of two kinds. First, the histological appearances suggest a neoplastic process; and secondly, the condition bears no apparent relation to trauma, infection, metabolic or developmental processes.

If osteoid osteoma is a benign neoplasm, there are three clinical features of the condition which demand explanation-namely the severe pain, the widespread bone sclerosis spreading well beyond the histological limits of the lesion, and the self-limiting course which the tumour appears to run. It seems at first sight that these features are not compatible with the behaviour of a neoplasm. However, they may all be explained by its remarkably vascular nature. The increased tension which develops in an inflammatory lesion from vasodilation and oedema causes pain by the direct stimulation of local nerve endings. Bone lesions associated with vasodilation and oedema, such as acute osteomyelitis, Paget's disease, and osteogenic sarcoma, produce pain presumably in the same way by direct stimulation of the nerve endings around the intra-osseous vessels. If a microscopical section cut through an osteoid osteoma is examined under polarised light the trabeculae can be observed to radiate from the central focus to merge at the periphery with the normal trabecular pattern. If it is assumed that trabeculae are arranged to withstand the stress to which a bone is subjected, this radial arrangement can only mean that an osteoid osteoma exerts pressure upon the surrounding bone, presumably because of its vascular nature. This evidence of increased pressure suggests that the pain is produced by the highly vascular tumour lying within the confines of the sclerosed bony trabeculae (Case 4).

\section{CASE REPORT}

Case 4 (Mr Philip Wiles's case). Osteoid osteoma of the second metacarpal-A boy of eighteen complained of a lump on the back of the right hand which had appeared a year before. There had been a dull pain, worse at night. Radiographs showed a fusiform enlargement of the shaft of the metacarpal with patchy sclerosis and irregular trabeculae (Fig. 8) but no definite cavity or nidus was visible. A diagnosis of osteoid osteoma was thought probable.

As a clinical test, a pneumatic tourniquet was applied to the upper arm and inflated to above the systolic pressure. This rapidly relieved the discomfort.

At operation the affected area of the metacarpal shaft was excised except for the palmar cortex. A piece of rib from the bone bank was used to repair the defect.

Histological examination (Dr A. D. Thomson) confirmed the diagnosis of osteoid osteoma. Since operation the patient has remained free from symptoms.

Bone sclerosis extending beyond the histological confines of a bone lesion is not an unusual finding. Benign angiomata of bone (Bucy and Capp 1930) are transradiant where the vascular neoplastic tissue lies, but around this, in long-standing cases, marked sclerosis may be evident. This appearance is found in the "sun-burst" angioma of long bones, the "soap-bubble" angioma of flat bones, as well as the commoner angioma of the vertebral bodies. Other conditions may be accompanied by such sclerosis, especially in the young. 
Cushing (1922), Kolodny (1929), Rowbotham $(1939,1942)$ and others, discussing the peculiar hyperostoses on the skull which accompany an underlying vascular meningioma, have suggested that an alteration in the blood supply is the essential factor in producing these hyperostoses. Kolodny (1929) and Rowbotham (1939) believed that the vascular lesion puts the bone into a state of metabolic activity, particularly around the venous sinuses draining the tumour, and commented on the extremely slow growth of the lesions. Kolodny also stressed the fact that the most massive reactions occur in the young, stating his belief that it is the dilating vascular channels that result in new bone formation.

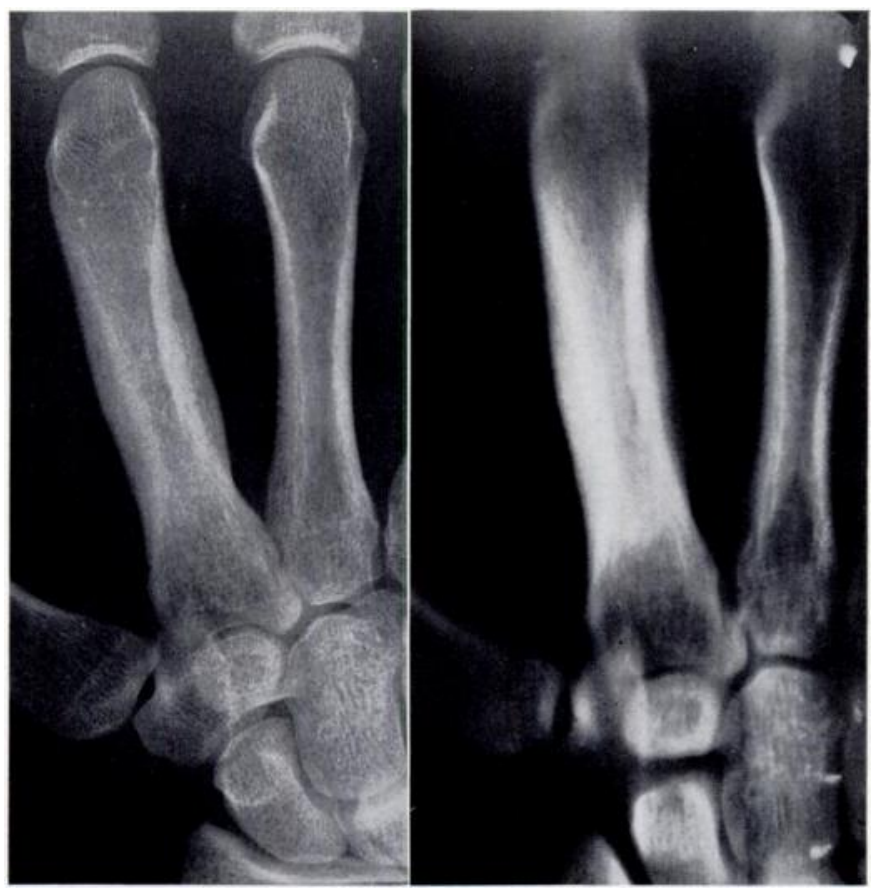

FIG. 8

Case 4-Plain radiograph (left) and a tomograph of the second metacarpal. The expansion of the shaft can be seen in the plain radiograph, but the exact position of the nidus is apparent only in the tomograph.

Spontaneous retrogression-a self-limiting course-is characteristic of cutaneous congenital haemangiomata. Thomas (1942), analysing vascular bone tumours, defined benign angioma of bone as "a slow growing highly differentiated tumour, congenital in origin, with definite well formed blood vessels and an innate tendency to regress and heal." It is suggested that spontaneous thrombosis is the cause of this self-limiting course of vascular haemangiomata, and it may well be that the self-limiting course of an osteoid osteoma is due to the spontaneous thrombosis of the blood vessels within it.

\section{TREATMENT}

There is general agreement that complete excision of an osteoid osteoma is the treatment of choice. In five of the cases $(12,15,16,17$ and 19) reported here the opinion expressed by Ponseti and Barta (1947) that incomplete excision leads to the recurrence of symptoms was confirmed. Usually the affected bone is easily accessible to surgery and little difficulty is experienced in excising completely a block of bone containing the central cavity. Mayer (1951) described his treatment of the less accessible lesions and showed how much can be done to obtain complete excision by a carefully planned surgical approach. Curettage of the cavity is not advised because if it is not thoroughly performed the lesion is liable to recur.

VOL. $36 \mathrm{~B}$, NO. 2 , MAY 1954 


\section{CASE REPORT}

Case 5 (Sir Harry Platt's case). Osteoid osteoma of calcaneum-A girl aged nine complained of pain and swelling of the left ankle of one year's duration, worse for four months. The pain was severe. On examination, a soft elastic swelling was observed over the left calcaneum and there was obvious wasting of the calf. A diagnosis of low-grade osteomyelitis was entertained and she was admitted to hospital. The white blood count was normal. A radiograph showed an area of slight sclerosis below the sustentaculum tali with a small transradiant area within it. A further radiograph two months later showed marked sclerosis around an apparently cystic area in the calcaneum. The symptoms continued in spite of rest in bed.

At operation the cavity was gouged out of the cancellous bone but a subsequent radiograph showed part of the lesion to be still present. Histological examination (Professor S. L. Baker) showed the lesion to be an osteoid osteoma.

The pain recurred and at a further operation the lesion was removed completely. Since then the patient has remained free from pain.

Even if curettage removed the osteoid osteoma completely, considerable difficulty might be encountered in the histological interpretation of the damaged material obtained. There is a risk that an osteoid osteoma might be mistaken for an osteogenic sarcoma, or vice versa, with serious consequences.

There are situations that are not easily accessible even to the most carefully planned exposure. In such a case complete excision of the tumour might result in symptoms more severe than those of the original condition. Since it is probable that the symptoms are caused by the vascular nature of the lesion, it is suggested that in such exceptional cases a trial course of radiotherapy should be used before surgery. is attempted.

\section{CONGLUSIONS}

An osteoid osteoma is a benign neoplasm of bone with distinctive clinical signs and symptoms. It is a pathological entity. It behaves in a way peculiar amongst benign tumours in that it is painful, causes widespread bone sclerosis outside its histological margins, and runs a self-limiting course. These three features are consequent on the highly vascular nature of connective tissue matrix in the early stages of the maturing lesion. Pain occurs in other highly vascular lesions within a confined space. There is evidence that there is increased tension within the sclerosed bone. Certain other vascular lesions within bone result in widespread sclerosis outside the confines of the lesion, particularly in young subjects. By analogy with the angiomata of skin and bone, spontaneous regression and a self-limiting course might be expected.

\section{SUMMARY}

1. The clinical features in twenty cases of osteoid osteoma have been analysed and compared with other cases reported in the literature.

2. The lesion is regarded as a benign neoplasm and its unusual clinical behaviour is attributed to its vascular nature.

3. The frequency with which an erroneous diagnosis of " neurosis" is made is stressed.

My thanks are due to the surgeons who have allowed me to examine the records of their cases and whose names appear in the text. I particularly acknowledge the help given me by Sir Reginald Watson-Jones who instigated this work, and by Professor S. L. Baker and Dr H. A. Sissons who have advised me on much of the pathological material.

\section{REFERENCES}

Brown, R. C., and Ghormley, R. K. (1943): Solitary eccentric (cortical) abscess in bone. Surgery, $14,541$. BuCY, P. C., and CAPP, C. S. (1930): Primary Hemangioma of Bone. American Journal of Roentgenology, 23, 1 .

Chandler, F. A., and Kaell, H. I. (1950): Osteoid-Osteoma. Archives of Surgery, 60, 294.

Compere, E. L. (1932): Streptococcus viridans Osteomyelitis. Journal of Bone and Joint Surgery, $14,244$. Cushing, H. (1922): The Cranial Hyperostoses Produced by Meningeal Endotheliomas. Archives of Neurology and Psychiatry, 8, 139. 
Dockerty, M. B., Ghormley, R. K., and Jackson, A. E. (1951): Osteoid Osteoma. Annals of Surgery, 133, 77.

Jackson, A. E. (1949): Osteoid Osteoma: A Clinical Study of 20 Cases. Proceedings of the Staff Meetings of the Mayo Clinic, 24, 380.

JAFFE, H. L. (1935): “ Osteoid-Osteoma." Archives of Surgery, 31, 709.

JAFFe, H. L. (1945): Osteoid-Osteoma of Bone. Radiology, 45, 319.

JAfFe, H. L., and Lichtenstein, L. (1940): Osteoid Osteoma: Further Experience with this Benign Tumor of Bone. Journal of Bone and Joint Surgery, 22, 645.

Kolodny, A. (1929): Cranial Changes Associated with Meningioma. Surgery, Gynecology and Obstetrics, 48, 231.

Mackenzie, W. (1947): Painful, non-suppurative, localized Sclerosis of the Long Bones. Journal of Bone and Joint Surgery, 29, 49.

MAYER, L. (1951): Surgery of Osteoid Osteoma. Bulletin of the Hospital for Joint Diseases, 12, 174.

Moberg, E. (1951): The Natural Course of Osteoid Osteoma. Journal of Bone and Joint Surgery, 33-A, 166. Palmer, I. (1945): A Peculiar Bone Tumour. Acta Chirurgica Scandinavica, 92, 387.

Ponseti, I., and Barta, C. K. (1947): Osteoid Osteoma. Journal of Bone and Joint Surgery, 29, 767.

Rowвотнам, G. F. (1939): The Hyperostoses in Relation with the Meningiomas. British Journal of Surgery, 26, 593.

Rowвотнам, G. F. (1942): Haemangiomata arising in the Bones of the Skull. British Journal of Surgery, 30, 1.

Sherman, M. S. (1944): Capillary Hemangioma of Bone. Archives of Pathology, 38, 158.

Sherman, M. S. (1947): Osteoid Osteoma Associated with Changes in Adjacent Joint. Journal of Bone and Joint Surgery, 29, 483.

Sherman, M. S. (1947): Osteoid Osteoma. Journal of Bone and Joint Surgery, 29, 918.

Thомas, A. (1942): Vascular Tumors of Bone. Surgery, Gynecology and Obstetrics, 74, 777.

Vaughan-Jackson, O. J. (1950): Osteoid Osteoma with Unusual Symptoms. Journal of Bone and Joint Surgery, 32-B, 368.

\section{APPENDIX}

\section{SUMMARISED REPORTS OF THE REMAINING 15 CASES UPON WHICH THE PAPER IS BASED}

Case 6 (Sir Harry Platt's case). Osteoid osteoma of humerus-A man aged twenty-eight complained of constant aching pain in the upper arm of nine months' duration. The pain was not related to activity. On examination the only abnormal physical sign was an area of tenderness over the outer aspect of the middle third of the shaft of the humerus where a small elevation was palpable.

At operation a superficial cortical defect was observed. This was excised with a block of bone including the whole lesion. He has been free of pain since the operation.

Histological examination (Dr J. Ball) confirmed osteoid osteoma. There was a nodule of osteoid tissue five millimetres in diameter embedded in dense cortical bone. There was some new bone formation in the centre of the nodule and the surrounding cortex showed evidence of absorption and deposition of new bone rather similar to that seen in Paget's disease.

Case 7 (Sir Reginald Watson-Jones's case). Osteoid osteoma of metacarpal-A boy aged thirteen complained of pain in the hand of three months' duration. On examination, no swelling was palpable. A radiograph showed fusiform expansion of the shaft of the third metacarpal which was thickened and somewhat sclerosed. Rest in plaster relieved the pain except when the hand was warm. At a subsequent review the diagnosis of osteoid osteoma was made. The lesion was excised. When the patient was last seen nine months after operation he was free of pain. Histological examination of the specimen showed an osteoid osteoma mainly ossifying and partly incorporated in the corticalis.

Case 8 (Sir Reginald Watson-Jones's case). Osteoid osteoma of the second lumbar vertebra-A man aged twenty-seven complained of a dull ache in the upper lumbar region of two years' duration. The pain radiated round the right side of the pelvis to the lateral aspect of the thigh. It was severe at night and was relieved by taking aspirin. On examination a scar at the level of the upper lumbar spine was found where the area had been explored a year previously for a suspected bomb fragment. There was a marked right scoliosis. Hyperextension and flexion of the lumbar spine were limited. Radiographs showed narrowing of the intervertebral discs but no other abnormality. The pain persisted despite a spinal support. Further radiographs six weeks later including tomograms by Dr Campbell Golding showed.a lesion involving the inferior articular process and lamina on the right side of the second lumbar vertebra.

At operation a cavity was found in the pars interarticularis and inferior articular process. The walls of the cavity were sclerosed and the surrounding tissue was fibrotic and adherent to the bone. The cavity was curetted. The tissue removed resembled subperiosteal callus. Since

vol. $36 \mathrm{~B}$, No. 2. MAY 1954 
the operation the patient has remained free of pain. Histological examination showed anastomosing trabeculae of osteoid tissue and woven bone separated by fibrous tissue and containing numerous osteoblasts and fewer osteoclasts.

Case 9 (Lt.-Col. R. Stevens's case). Osteoid osteoma of femur-A man aged twenty-five complained of pain in the left thigh of three years' duration. The pain was a severe ache, worse after exercise, and it radiated from the upper thigh to the knee. It was relieved by aspirin. He had visited many medical officers in the Forces and six months previously had been admitted to a Naval hospital under the care of a psychiatrist. On examination there was slight wasting of the thigh with tenderness over the antero-lateral aspect of the lower third of the femur. A radiograph showed a fusiform enlargement of the lower third of the femur with considerable sclerosis around a small cavity typical of an osteoid osteoma.

At operation (Lt.-Col. Marsden) the lesion was excised from the femur in a block of bone. Histological examination confirmed osteoid osteoma.

Case 10 (Mr P. H. Newman's case). Osteoid osteoma of femur-A girl aged fourteen complained of a severe worsening deep ache in the front of the left thigh of three months' duration. The pain tended to shoot into the buttock and down the front of the leg to the ankle. The pain hindered sleep, but it was relieved by aspirin. On examination the only abnormality was slight tenderness over the anterior and lateral aspect of the thigh. Radiographs showed marked sclerosis on the medial surface of the mid-shaft of the femur with a small chink-like area suggestive of a cavity within it. A diagnosis of osteoid osteoma was made.

At operation massive sclerosis was encountered. No definite nidus was seen although one area was found to be softer than the rest; the whole was excised. The patient has remained free of pain since operation. Histological examination confirmed the diagnosis (Dr A. D. Thomson).

Case 11 (Lt.-Col. C. Marsden's case). Osteoid osteoma of tibia-A boy aged eighteen complained of an aching pain in the right tibia, which had begun eight months before. The onset followed a kick. The pain was a dull ache, severe at night. Radiographs showed sclerosis in the uppermost third of the tibia, which was enlarged on its subcutaneous aspect, and a cavity with an irregular area of sclerosis within it. At operation the cavity was found to be lying in dense sclerosed bone. It contained a cherry red area of gritty friable material with a dense white central nidus. The patient has remained free of pain. The histological report confirmed that the lesion was an osteoid osteoma.

Case 12 (Mr E. A. Nicoll's case). Osteoid osteoma of tibia-A man aged twenty-six complained of severe aching pain in the left shin for one year. The pain was worse at night but was relieved by aspirin. A radiograph showed extensive sclerosis around a small cavity. A small central nidus was visible. A diagnosis of osteoid osteoma was made.

At operation the lesion was excised and a soft red-brown gritty nidus was identified. The patient has remained free of pain. Histological examination (Figs. 5 and 6) showed a vascular matrix of spindle cells with numerous osteoclasts. There were irregular trabeculae of osteoid tissue and areas showed marked calcification.

Case 13 (Lt.-Col. C. Marsden's case). Osteoid osteoma of tibia-A boy of eighteen complained of a severe aching pain in the lowest third of the left tibia for six months. The pain started one month after a kick on the shin. It was worse at night and was relieved by aspirin. A radiograph showed marked sclerosis around a small cavity in the lowest third of the tibia.

At operation the central lesion was seen to be pale pink in colour and friable. A local excision was carried out. The patient was free of pain for a month, during which time the histological examination had confirmed the diagnosis of osteoid osteoma. The pain recurred and it was decided to re-explore the lesion. The whole area was excised, since when the patient has remained free of pain.

Case 14 (Mr John Charnley's case). Osteoid osteoma of tibia-A boy aged fourteen complained of a tender swelling over the front of the left tibia. Five years previously he had fallen and bruised the left shin and there had been a small lump at this site ever since. On examination there was a fusiform swelling of the anterior surface of the tibia and the temperature of the overlying skin was increased. A radiograph showed an extensive area of sclerosis in the tibia but no cavity was visible. In the next six months the swelling increased and the patient complained of a dull ache. A later radiograph showed a central cavity within the dense sclerosed bone. A diagnosis of osteoid osteoma was made.

At operation the tibia was explored by removing slices of bone over the apex of the swelling. These slices were seen to be heavily penetrated with blood vessels which gave the bone a porous appearance. There was seen to be an area communicating with the marrow cavity containing dark red material resembling an old haematoma. Since the operation the patient has been free of symptoms. 
Case 15 (Mr John Charnley's case). Osteoid osteoma of tibia-A girl aged thirteen complained of pain and swelling over the left tibia, of six months' duration. A limp developed. On examination there was tenderness below the tibial tubercle, and thickening of the tibia in its middle third. A radiograph showed dense sclerosis and fusiform expansion of the shaft of the bone with a smaller cystic space within the zone of sclerosis. A diagnosis of osteoid osteoma was made but the child's mother refused to allow her admission to hospital. Six months later the pain had become more severe and operation was consented to. At operation the tibia was seen to consist of solid cortical bone with no definite medullary cavity. Since the operation the patient has remained free of pain. The specimen was examined by Professor S. L. Baker, who reported that there was a network of osteoid tissue in a vascular spindle cell matrix. There was evidence of great osteoblastic activity around the areas of osteoid tissue.

Case 16 (Sir Reginald Watson-Jones's case). Osteoid osteoma of tibia-A man aged twenty-three complained of severe aching pain in the right tibia of three years' duration. There was no history of injury. The pain was relieved by aspirin. A diagnosis of chronic osteomyelitis had previously been made elsewhere and the bone had been drilled with temporary relief of pain. It had then been suggested that it was a Ewing's sarcoma and amputation had been proposed. Radiographs showed dense sclerosis and subperiosteal new bone formation surrounding a slit-like defect in the lower shaft of the tibia with an enclosed area of condensation. When the bone was exposed there was brown pigmentation of the overlying periosteum. The cortical bone was extraordinarily hard and dense, and with much difficulty it was chiselled away until a bright red vascular nodule like a raspberry was disclosed and removed (Fig. 2). Histological appearance was typical. In the three years since operation there has been no recurrence of pain and radiographs now show resorption of the sclerosed bone. Case 17 (Mr J. C. R. Hindenach's case). Osteoid osteoma of tibia-A boy aged thirteen complained of three months' pain from the left knee to the ankle, worse at night and relieved by exercise. On examination there was a tender enlargement of the middle third of the postero-medial aspect of the tibia. The overlying skin was warmer than normal. Radiographs showed subperiosteal new bone formation and sclerosis at the middle third of the tibia. No transradiant area was visible. Biopsy showed osteoid osteoma. At operation a cavity containing plum-coloured gritty material was exposed within dense sclerosed bone. The lesion was excised. The patient has remained free of pain. Histological examination showed a highly cellular and vascular stroma with giant cells and areas of calcification and ossification. The osteoid tissue was less pronounced than usual but the appearances were typical of an osteoid osteoma.

Case 18 (Sir Harry Platt's case). Osteoid osteoma of tibia-A girl aged thirteen years complained of seven months' pain in the right leg. The pain was severe at night. On examination there was a tender thickening of the middle third of the tibia. Radiographs showed dense cortical thickening and sclerosis around a small rather ill-defined area of transradiancy.

At operation the affected area was "guttered." The periosteum was a little thick and the surface of the cortical bone appeared unusually dense. The patient was relieved of pain for a few months but it gradually recurred. At a further operation the whole sclerotic area was excised. Thereafter she was free of pain. Histological examination (Professor S. L. Baker) showed the typical appearance of osteoid osteoma.

Case 19 (Mr R. Roaf's case). Osteoid osteoma of fibula-A boy aged sixteen complained of increasing pain in the right ankle of nine months' duration. On examination the only abnormal finding was some thickening around the lower end of the left fibula. A radiograph showed a cavity surrounded by a zone of sclerosis with enlargement of the fibula about three inches above the ankle. A Brodie's abscess was suspected because no nidus was seen within the cavity.

At operation the cavity was found to contain yellowish putty-like material lying in normal marrow. The whole of the area was removed. The patient has been relieved of all symptoms. Histological examination showed a vascular spindle-cell stroma with much osteoid tissue and early calcification. Many osteoclasts were present.

Case 20 (Mr K. I. Nissen's case). Osteoid osteoma of metatarsal-A man aged twenty-one complained of increasing pain and swelling of the forefoot, arising one year previously after a blow. The pain was relieved by codeine tablets. A diagnosis of an old march fracture had been suggested. On examination there was palpable swelling over the distal half of the second metatarsal which was slightly tender. A radiograph showed what appeared to be a small cavity within a zone of dense sclerosis in the metatarsal.

At operation a pink mass of gritty material was seen to be occupying the shaft of the second metatarsal. The surrounding bone was sclerosed. The lesion was excised. The patient has remained free of pain. Histological examination (Dr H. A. Sissons) showed a central focus of woven bone and fibrous tissue rich in osteoclast giant cells and highly vascular. Bone erosion was proceeding at the margin of the central focus but the surrounding cortex showed diffuse sclerosis.

vol. 36 B, NO. 2, MAY 1954 